\title{
Seizures in Children under Five in a Pediatric Ward: Prevalence, Associated Factors and Outcomes
}

\author{
Abdoul Karim Doumbia1*, Oumou Koné2, Guédiouma Dembélé3, Adama Dembelé1,

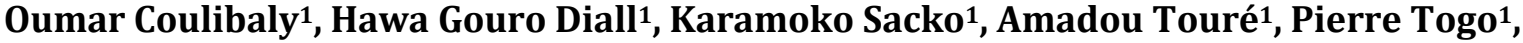 \\ Abdoul Aziz Diakité1, Mohamed Elmouloud Cissé1, Belco Maiga1, Djeneba Konaté1, \\ Fatoumata Léonie Diakité ${ }^{3}$, Lala N'drainy Sidibe', Fousseyni Traoré1 ${ }^{1}$, Adama Bah ${ }^{1}$, \\ Djibril Kassogue1, Boubacar Togo', Madou Traoré1 \\ ${ }^{1}$ Department of Pediatrics at CHU Gabriel Touré, Bamako, Mali \\ ${ }^{2}$ National Institute of Public Health, Bamako, Mali \\ ${ }^{3}$ Mohammed VI Perinatal Clinic, Bamako, Mali \\ Email: ^doumbiav@gmail.com
}

How to cite this paper: Doumbia, A.K., Koné, O., Dembélé, G., Dembelé, A., Coulibaly, O., Diall, H.G., Sacko, K., Touré, A., Togo, P., Diakité, A.A., Cissé, M.E., Maiga, B., Konaté, D., Diakité, F.L., Sidibe, L.N., Traoré, F., Bah, A., Kassogue, D., Togo, B. and Traoré, M. (2021) Seizures in Children under Five in a Pediatric Ward: Prevalence, Associated Factors and Outcomes. Open Journal of Pediatrics, 11, 627-635. https://doi.org/10.4236/ojped.2021.114058

Received: September 20, 2021 Accepted: November 14, 2021 Published: November 17, 2021

Copyright $\odot 2021$ by author(s) and Scientific Research Publishing Inc. This work is licensed under the Creative Commons Attribution International License (CC BY 4.0).

http://creativecommons.org/licenses/by/4.0/

\begin{abstract}
Introduction: convulsion is a frequent cause of neurological and cognitive sequelae and then of epilepsy. The objective of this work was to describe the socio-demographic, clinical, therapeutic, and evolutionary aspects. Methodology: This was a descriptive retrospective study carried out in the general pediatrics department of CHU-Gabriel Touré. It took place over a period of 02 years from January 2017 to December 2018. We included all children aged 1 to 59 months hospitalized in the ward for convulsion. Results: During the study period, 2653 children aged 2 months to 59 months were hospitalized in the general pediatric ward. We included 288 medical records of children who presented with a seizure on admission. Convulsions represented $11 \%$ of pediatric hospitalizations from 1 month to 59 months. The average age was 29 months. Fever was present in $86 \%$ of patients. The cerebrospinal fluid (CSF) test was positive in 38 patients. Hypoglycemia was present in 14 patients. Serum calcium was low in 3 patients. The most implicated etiologies were malaria $70 \%$, meningitis $20 \%$, and dehydration $13 \%$. Management consisted of airway clearance, oxygen therapy as needed, and administration of diazepam (54\%). Antibiotics were prescribed in $77 \%$ of cases and antimalarials in $70 \%$. The average length of hospital stay was 8 days with extremes of 1 and 30 days. The outcome was favorable in $95 \%$ of cases. Sequelae were observed in $5 \%$ of cases and one case of death was observed. Conclusion: Acute convulsions are one of the most common causes of hospitalization in children under 5 years old. The causes were dominated by infectious diseases (malaria, meningitis).
\end{abstract}


The appropriate course of action was the administration of diazepam rectally.

\section{Keywords}

Convulsions, Child, Infant, Prognosis, Sub-Saharan Africa

\section{Introduction}

Convulsion is a frequent cause of admission to pediatrics and a provider of neurological and cognitive sequelae [1]. Many authors currently prefer the term epileptic seizure to the end of convulsion, even if it is occasional or isolated. The incidence of seizures is higher in children under 5 years of age [2]. In the United States, seizures account for about $2 \%$ of emergency department visits in children's hospitals [3]. Their prevalence is much higher in tropical countries [4]. They have various aetiologies dominated mainly in sub-Saharan Africa, by infections of the central nervous system ( $80 \%$ of cases) [4] [5]. The prognosis depends on the causal pathology and the severity of the seizures. The convulsion is simple and benign in the vast majority of cases. The acute and febrile forms are more common in children under 5 years old [1] [3] [6]. Etiologic research requires detailed clinical examination, laboratory and imaging examinations [4] [5]. Computed tomography should not be routine unless there is a suggestive clinical history or persistent disturbances of consciousness [6] [7]. The cost of these investigations is a major concern in poor countries. While a misdiagnosis also carries a potential risk that can cause family anxiety, excessive hospital stay and possibly fatal events [3]. Seizures are associated with a high risk of cerebral palsy, epilepsy, and death, but the prognosis appears to be more related to the etiology and extent of brain damage than to the seizures themselves [1].

Data on acute seizures in developing countries are scarce. The current study aims to explore the epidemiological, diagnostic and evolutionary aspects of seizures in infants and children under 5 in hospital settings.

\section{Methodology}

The study took place in the general pediatrics department of the Gabriel Toure university hospital (CHU) in Bamako in the capital of Mali. It is a $3^{\text {rd }}$ reference structure (the top of the health pyramid), located in the city center in commune III of the district of Bamako. The pediatrics department is made up of three services which are:

1) The neonatal department ( 82 hospital beds);

2) The pediatric emergency department (22 hospital beds);

3) The general pediatric service.

The general pediatric service has 72 beds and receives an average of $2162 \mathrm{pa}-$ tients per year, $55 \%$ of whom are referred by other health structures. The general pediatric service mainly provides curative care. It includes 4 units: 
- Pediatrics 1: 22 beds;

- Pediatrics 2: 24 beds;

- Pediatrics 4: 16 beds;

- And the Pediatric Oncology Unit: 10 beds.

This was a retrospective, descriptive study carried out in the general pediatrics department of the CHU Gabriel Touré. This study was carried out from January 2017 to December 2018. The study concerned children aged 1 month to 59 months admitted to the pediatric ward.

We retrospectively included the medical records of patients hospitalized in the general pediatric department of CHU Gabriel Touré for convulsion during the study period. The patients had all been initially seen in the pediatric emergency room by an intern or a senior, then transferred to the general pediatric ward. We did not include in this study children with poorly completed or poorly kept records.

Data collection was done on a survey sheet from medical records and service registers. The variables studied were socio-demographic, clinical and paraclinical (biology, cerebral imaging, electroencephalogram (EEG)), diagnostic and evolutionary data. Lumbar punctures had been performed according to a standard protocol, with the exception of cases of contraindication in order to exclude any damage to the central nervous system.

The data had been analyzed using Statistical Software for the Social Sciences (SPSS), version 20.0 .

The fever was defined by a rectal temperature at rest greater than or equal to $38.5^{\circ} \mathrm{C}[8]$

Anemia was defined as a decrease in hemoglobin level below $11 \mathrm{~g} / \mathrm{l}$ in young children [8]; it was considered serious if the hematocrit level $<15 \%$ or hemoglobin level $<5 \mathrm{~g} / \mathrm{dL}[8]$.

The health administrative authorities of the Gabriel Touré University Hospital and the heads of departments and units had given their authorization for this work to be carried out. The confidentiality of the data collected was guaranteed.

\section{Results}

\subsection{Epidemiological Aspects}

During the study period, 2653 children aged 2 months to 59 months were hospitalized in the general pediatric ward. Among them, 288 children presented with a seizure on admission (i.e. a prevalence of 11\%), the male sex was overrepresented with a sex ratio of 1.38 and a half (48\%) were under 24 months (Table 1). Vaccination status was correct for age and the Expanded Program on Immunization (EPI) in $84 \%$ of patients.

\subsection{Clinical aspects (Table 2)}

The seizures were generalized tonic-clonic in $93 \%$ of cases and repetitive in $49 \%$ of cases. The duration of the attacks exceeded 15 minutes in $9 \%$ of cases. The 
Table 1. Distribution of patients by age and sex.

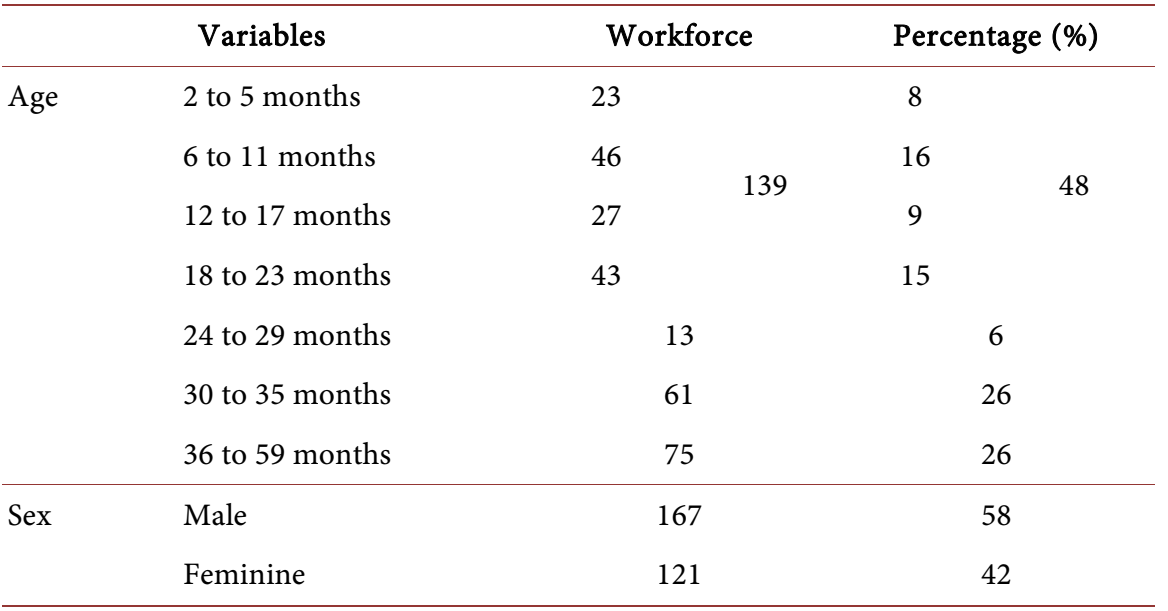

Table 2. Distribution of patients according to the characteristics of the attacks.

\begin{tabular}{|c|c|c|c|}
\hline & Variables & Workforce & Percentage (\%) \\
\hline \multirow{5}{*}{$\begin{array}{l}\text { Characteristics of } \\
\text { seizures }\end{array}$} & Partial & 29 & 10 \\
\hline & Generalized tonic-clonic & 267 & 93 \\
\hline & Myoclonus & 9 & 3 \\
\hline & Spasms & 12 & 4 \\
\hline & Repetitive & 142 & 49 \\
\hline \multirow[t]{2}{*}{ Duration of the crisis } & Less than or equal to 15 minutes & 263 & 91 \\
\hline & Greater than 15 minutes & 25 & 9 \\
\hline \multirow[t]{11}{*}{ Clinical signs } & Fever & 249 & 86 \\
\hline & Pallor & 90 & 31 \\
\hline & Postcritical coma & 67 & 23 \\
\hline & Respiratory distress & 46 & 16 \\
\hline & Dehydration & 42 & 15 \\
\hline & Hepatomegaly & 41 & 14 \\
\hline & Motor deficit & 16 & 6 \\
\hline & Splenomegaly & 14 & 5 \\
\hline & Meningeal syndrome & 11 & 4 \\
\hline & Macrocrania & 5 & 2 \\
\hline & Bulging fontanel & 4 & 1 \\
\hline
\end{tabular}

results show that $7 \%$ of the children were underweight. Fever was present in $86 \%$ of patients. Dehydration was found in $15 \%$ of patients.

\subsection{Paraclinical Aspects}

Hypoglycemia was observed in $10 \%$ of patients. Serum calcium was low in a quarter of the patients. Lumbar puncture was performed in $65 \%$ of patients. The 
CSF was cloudy in $2 \%$ of the children. The leukocyte count was abnormally high in the CSF in $20 \%$ of the patients. Thick gout was positive in $71 \%$ of patients. In addition, the blood count found severe anemia (hemoglobin level below $8 \mathrm{~g} / \mathrm{dl}$ ) in $47 \%$ of the children. CRP was elevated in $84 \%$.

The EEG was normal in 1 out of 5 cases. The CT scan was performed in 9 cases, it was pathological in 6 cases and had demonstrated cerebral atrophy ( 2 cases), an ischemic attack ( 2 cases), a left temporal cyst ( 1 case), retinoblastoma metastases (1 case). Malaria (70\%), meningitis (20\%) and dehydration (13\%) were the main etiologies of seizures. Hyperthermic seizures were diagnosed in $5 \%$ of the children.

\subsection{Evolving Therapeutic Aspects}

In addition to the administration of diazepam, management consisted of airway clearance and oxygen therapy as needed. Diazepam was administered intravenously in $91 \%$ of cases. Antibiotics were prescribed in $77 \%$ of cases and antimalarials in $70 \%$. The average length of hospital stay was 8 days with extremes of 1 and 30 days. The outcome was favorable in $95 \%$ of cases. Sequelae were observed in $5 \%$ of cases and one death was observed (Table 3 ).

\section{Comments and Discussions}

This retrospective hospital study of the files of children aged 2 months to 59 months, admitted to the pediatric emergency department of the CHU Gabriel Touré and/or hospitalized for convulsions, whether or not associated with a fever. It had made it possible to identify the epidemiological, clinical, therapeutic and progressive features of convulsions in children aged 1 month to 59 months. The occurrence of a seizure was a frequent reason for visiting the pediatric emergency room. Admission rates for seizures were as high as $25 \%$ in some sub-Saharan studies [5] [9]. The incidence of seizures is likely higher in developing countries [5] [10]. Half of the patients were infants with the majority being boys. These results were similar to the data in the literature [2] [5] [11]. The high incidence during the young age would depend on the immaturity of the vegetative system, genetic and environmental factors intervening especially in a feverish context [12] [13] [14]. In most cases, the convulsions occurred in a feverish context. As the doctor generally only has the simplest additional examinations,

Table 3. Distribution of patients by outcome.

\begin{tabular}{ccc}
\hline Evolution & Workforce & Percentage (\%) \\
\hline Favorable & 273 & 95 \\
Sequelae & 14 & 5 \\
Death & 1 & $<1$ \\
Exit against medical advice/escapees & 5 & 2 \\
\hline
\end{tabular}


the aetiological diagnosis is mainly based on examination and clinical examination. Diagnosis should first be sought for central nervous system (CNS) infection [1] [5] [15]. Acute seizures in young children are associated with infections in more than $80 \%$ of cases as reported in the literature [5] [11]. The performance of additional examinations and the indication of antiepileptic treatment should be based mainly on the analysis of signs of seriousness. Lumbar puncture is discussed in the event of complex or atypical seizures (lasting more than $15 \mathrm{mi}$ nutes, focal seizure or repeated seizures) or in the event of impaired consciousness or neurological deficit [16]. The two main contraindications for lumbar puncture are intracranial hypertension linked to a mass effect and a significant abnormality of uncorrected hemostasis [17]. The indication of PL in the event of a convulsion should therefore be based on the demonstration of significant signs of CNS involvement on clinical examination [1] [5] [6]. Clinical examination and electroencephalogram (EEG) are good indicators of neuroimaging [6] [18]. Computed tomography is generally indicated in states of convulsive pain, in cases of persistent neurological abnormalities, in non-febrile seizures [6] [15]. Very expensive Magnetic Resonance Imaging (MRI) is a gold standard for the exploration of seizures due to its high resolution, versatility and absence of radiation [15]. Co-morbidities such as hypoglycemia, electrolyte disturbances (hyponatremia, hypocalcemia, hypomagnesemia) and severe anemia were almost constant [19] [20].

Cerebral malaria was the main cause of febrile seizures, as in most studies in the subregion [21] [22]. According to the literature, the risk factors significantly associated with the onset of meningitis are age less than 12 months, lethargy, irritability, vomiting, stiff neck, bulging fontanel, headache., drowsiness, coma, complex seizures and previous use of antibiotics [23] [24] [25]. In this study, the majority of cases of meningitis occurred in infants. In Western studies, febrile seizures $(\mathrm{CF})$ are the most common epileptic syndrome seen in children between the ages of 6 months and 6 years. Their frequency is estimated between 2 and $5 \%$. It has been defined by the National Institute of Health as "an event occurring in an infant or child between three months and five years of age associated with fever, without evidence of intracranial infection or any other defined cause. Convulsive seizures with fever occurring in children who have had a non-febrile seizure in their history are excluded from the definition" [12] [15] [26].

Since most of these were brief attacks, diazepam was not prescribed routinely. It was especially reserved for prolonged ( $>5$ to $10 \mathrm{~min}$ ) and/or repeated seizures. According to the literature, apart from specific situations (state of illness, underlying etiology with high potential for recurrence), it is not reasonable to offer long-term treatment [15]. Obviously, optimal management depends on the etiology and severity of the attack [7]. Hospitalization mainly concerned patients with signs of severity related to the seizure. Patient outcomes were mostly favorable but neurological sequelae were frequent (5\%). According to the literature, seizures are a major risk factor for cognitive and neurological disorders and the development of epilepsy in children under 5 years of age [9]. Children with a 
history of febrile seizures have a higher rate of epilepsy [27] [28]. Mortality is significantly higher in children with complex seizures compared to the general population [27] [28].

\section{Conclusion}

Seizures are a frequent reason for consultation in pediatric emergencies and remain dominated by febrile convulsions in infants. Despite its high frequency, complex clinical presentation and management difficulties, convulsion most often remains a benign pathology. The care is well codified and closely linked to the origin of the crises. The prognosis is closely linked to the management but above all to the etiology.

\section{Conflicts of Interest}

The authors declare no conflicts of interest regarding the publication of this paper.

\section{References}

[1] Idro, R., Gwer, S., Kahindi, M., et al. (2008) The Incidence, Aetiology and Outcome of Acute Seizures in Children Admitted to a Rural Kenyan District Hospital. BMC Pediatrics, 8, Article No. 5. https://doi.org/10.1186/1471-2431-8-5

[2] Friedman, M.J. and Sharieff, G.Q. (2006) Seizures in Children. Pediatric Clinics of North America, 53, 257-277. https://doi.org/10.1016/j.pcl.2005.09.010

[3] Martindale, J.L., Goldstein, J.N. and Pallin, D.J. (2011) Emergency Department Seizure Epidemiology. Emergency Medicine Clinics of North America, 29, 15-27. https://doi.org/10.1016/j.emc.2010.08.002

[4] Adhikari, S., Sathian, B., de Koirala, P.D. and Rao, K.S. (2013) Profil des enfants admis avec des convulsions dans un hôpital de soins tertiaires de l'ouest du Népal. BMC Pediatrics, 13, Article No. 43. https://doi.org/10.1186/1471-2431-13-43

[5] Agbèrè, A.D., Tatagan, K., Madikorai, M.G., Eklu-Avlasu, E., Balaka, B., Bakondé, B., et al. (1995) Les crises convulsives de l'enfant dans le service de pédiatrie du centre hospitalier régional de Kara (nord-Togo). Medecine d'Afrique Noire, 42, 310-314.

[6] Kaputu-Kalala-Malu, C. (2016) Epilepsies et crises épileptiques aiguës chez l'enfant en Afrique subsaharienne: Défis et espoirs. The Pan African Medical Journal, 23 Article No. 58.

[7] Ciccone, O., Mathews, M. and Birbeck, G.L. (2017) Management of Acute Seizures in Children: A Review with Special Consideration of Care in Resource-Limited Settings. African Journal of Emergency Medicine, 7, S3-S9. https://doi.org/10.1016/j.afjem.2017.09.003

[8] World Health Organization (2015) Memento de soins hospitaliers pediatriques: Prise en charge des affections courantes de l'enfance. World Health Organization, Geneva. https://www.who.int/about/licensing/copyright_form/en/index.html

[9] Assogba, K., Balaka, B., Touglo, F.A., Apetsè, K.M. and Kombaté, D. (2015) Convulsions fébriles chez des nourrissons âgés de moins de cinq ans dans la pratique tropicale: Fréquence, étiologie et résultats de l'hospitalisation. Journal of Pediatric Neurosciences, 10, 9-12. 
[10] Soto-Ares, G., Jissendi Tchofo, P. and Szurhaj, W. (2004) Conduite à tenir devant une première crise convulsive. Journal of Neuroradiology, 31, 281-288. https://doi.org/10.1016/S0150-9861(04)97007-1

[11] Mwipopo, E.E., Akhatar, S., Fan, P. and Zhao, D. (2016) Profil et caractérisation clinique des convulsions chez les enfants hospitalisés. The Pan African Medical Journal, 24, Article No. 313.

[12] Chen, C.Y., Chang, Y.J. and Wu, H.P. (2010) New-Onset Seizures in Pediatric Emergency. Pediatrics and Neonatology, 51, 103-111. https://doi.org/10.1016/S1875-9572(10)60019-8

[13] Berg, A.T., Shinnar, S., Levy, S.R. and Testa, F.M. (1999) Childhood-Onset Epilepsy with and without Preceding Febrile Seizures. Neurology, 53, 1742-1748 https://doi.org/10.1212/WNL.53.8.1742

[14] Graves, R.C., Oehler, K. and Tingle, L.E. (2012) Febrile Seizures: Risks, Evaluation, and Prognosis. American Family Physician, 85, 149-153.

[15] Ville, D. (2013) L'épilepsie de l'enfant. Contraste, 38, 37-57.

[16] Rasool, A., Choh, S.A., Wani, N.A., Ahmad, S.M. and Iqbal, Q. (2012) Role of Electroencephalogram and Neuroimaging in First Onset Afebrile and Complex Febrile Seizures in Children from Kashmir. Journal of Pediatric Neurosciences, 7, 9-15. https://doi.org/10.4103/1817-1745.97611

[17] Héritier, S., Torchin, H., Verstraete, A., de Suremain, N., Leverger, G., Carbajal, R. and Petit, A. (2018) La ponction lombaire chez l'enfant: Indications, réalisation et complications. La Revue du Praticien, 68, 426-430.

[18] Chaudhary, N., Gupta, M.M., Shrestha, S., et al. (2017) Clinicodemographic Profile of Children with Seizures in a Tertiary Care Hospital: A Cross-Sectional Observational Study. Neurology Research International, 2017, Article ID: 1524548. https://doi.org/10.1155/2017/1524548

[19] Huang, C.C., Chang, Y.C. and Wang, S.T. (1998) Acute Symptomatic Seizure Disorders in Young Children-A Population Study in Southern Taiwan. Epilepsia, 39, 960-964. https://doi.org/10.1111/j.1528-1157.1998.tb01445.x

[20] Nardone, R., Brigo, F. and Trinka, E. (2016) Acute Symptomatic Seizures Caused by Electrolyte Disturbances. Journal of Clinical Neurology, 12, 21-33.

[21] Chin, R.F., Neville, B.G. and Scott, R.C. (2005) Meningitis is a Common Cause of Convulsive Status Epilepticus with Fever. Archives of Disease in Childhood, 90, 66-69.

[22] Owusu-Ofori, A., Agbenyega, T., Ansong, D., et al. (2004) Routine Lumbar Puncture in Children with Febrile Seizures in Ghana: Should It Continue? International Journal of Infectious Diseases, 8, 353-361. https://doi.org/10.1016/j.ijid.2003.12.008

[23] Tinsa, F., El Ghrbi, A., Ncibi, N., et al. (2010) Role of Lumbar Puncture for Febrile Seizure among Infants under One Year Old. La Tunisie Medicale, 88, 178-183.

[24] Al-Eissa, Y.A. (1995) Lumbar Puncture in the Clinical Evaluation of Children with Seizures Associated with Fever. Pediatric Emergency Care, 11, 347-350. https://doi.org/10.1097/00006565-199512000-00004

[25] Casasoprana, A., Hachon Le Camus, C. and Claudet, L., et al. (2013) Value of Lumbar Puncture after a First Febrile Seizure in Children Aged Less than 18 Months. A Retrospective Study of 157 Cases. Archives de Pédiatrie, 20, 594-600.

[26] Saravanan, S. (2013) Profile of Children Admitted with Seizures in a Tertiary Care Hospital in South India. IOSR Journal of Dental and Medical Sciences, 11, 56-61.

[27] Ghotbi, F. and Shiva, F. (2009) An Assessment of the Necessity of Lumbar Puncture 
in Children with Seizure and Fever. Journal of Pakistan Medical Association, 59, 292-295.

[28] Vestergaard, M. and Christensen, J. (2009) Register-Based Studies on Febrile Seizures in Denmark. Brain and Development, 31, 372-377.

https://doi.org/10.1016/j.braindev.2008.11.012 